\title{
The role of diffusion barriers in determining the excitability of peripheral nerve
}

\author{
K. N. SENEVIRATNE AND O. A. PEIRIS \\ From the Departments of Physiology and Medicine, Faculty of Medicine, University of Ceylon, Colombo, \\ Ceylon
}

SUMMARY The excitability changes occurring in normal isolated peripheral nerves of rats have been studied during exposure to hypoxic and anoxic conditions before and after the administration of $\mathbb{D}$ insulin. The changes observed have been explained in terms of the dynamics of $K^{\prime}$ equilibrium in the periaxonal spaces, and attention is drawn to the importance of the relative impermeability of the periaxonal diffusion barrier in determining this equilibrium. Isolated peripheral nerves from alloxan-diabetic rats, studied under similar conditions, show significant differences in the sequence of their excitability changes. It has been shown that the rate of change of excitability in these nerves is slower than those of control nerves. These results have now been interpreted in terms of the $\mathrm{K}^{\prime}$ changes in the periaxonal space. It is concluded that these slower excitability changes are due to an $\dot{\omega}$ increase in the permeability of the diffusion barrier of the diabetic nerve to potassium.

Recent studies have drawn attention to the resistance of the peripheral nerve of diabetic subjects to inactivation by ischaemia (Steiness, 1959, 1961a and b; Castaigne, Cathala, Dry, and Mastropaolo, 1966; Gregersen, 1968). Seneviratne and Peiris (1968a and b), measuring the excitability changes in the median nerves during and after a 30 minute period of limb ischaemia, have demonstrated that the nerves of diabetic subjects do not show the phases of ischaemic and post-ischaemic hyperexcitability that are characteristic of the normal subject. The absence of the sensations of paraesthesiae in the diabetic subjects was attributed to the relatively small rate of change of excitability seen during the ischaemic and post-ischaemic phases. The most characteristic functional difference between the normal and diabetic nerves, however, was the very limited extent to which the diabetic nerve was inactivated by a 30 minute period of complete vascular occlusion. Seneviratne and Peiris (1969) have also demonstrated that the isolated peripheral nerves of alloxan-diabetic rats show a similar resistance in vitro to the effects of hypoxia.

Two alternative mechanisms could be responsible for this phenomenon. It has been suggested that diabetic nerves can maintain their activity under anoxic conditions by utilizing non-oxidative metabolic pathways. The experiments described in this paper were designed to test the alternative hypothesis suggested by Seneviratne and Peiris (1969) that the sequence of excitability changes during anoxi was determined by the dynamics of $\mathbf{K}^{\prime}$ equilibriug in the periaxonal space.

METHODS

Experimental diabetes was produced in 6-month-o rats weighing between 100 to $150 \mathrm{~g}$. A single dose of alloxan-monohydrate of $150 \mathrm{mg} / \mathrm{kg}$ body weight in freshly prepared citrate-phosphate buffer was injected intraperitoneally at a concentration of $10 \mathrm{mg} / \mathrm{ml}$. The criteria used to establish diabetes were a blood glucose 응 level of over $200 \mathrm{mg} / 100 \mathrm{ml}$. and a glycosuria of $1 \%$ or $\unrhd$ more. The animals were maintained in this condition $\overrightarrow{\vec{D}}$ for at least four weeks before being used for study. $\frac{3}{3}$ Litter mates of these rats and the alloxanized non- $\vec{Z}$ diabetic animals served as controls in the experiments described below. The rats were anaesthetized with intraperitoneal sodium pentobarbitone and the sciatic nerves dissected out rapidly from the level of the sciatic notch to the gastrocnemius tendon. The nerves were cleaned of fat and blood vessels, but the nerve sheath was left intact. The nerve was then immersed in mam- $\delta$ malian Tyrode's solution at $37^{\circ} \mathrm{C}$ and exposed to a gas mixture containing $95 \% \mathrm{O}_{2}+5 \% \mathrm{CO}_{2}$ for 15 。 minutes to minimize any injury activity. At the end of this period the nerve was mounted in a small moist $D$ nerve chamber containing platinum recording and stimulating electrodes and a gas inlet tube. The chamber $N$ was made air-tight and the nerve exposed to varying or gas mixtures which were admitted into the chamber $N$ at a constant flow rate. The gas mixtures used in these $\mathrm{N}$ experiments were $95 \% \mathrm{O}_{2}+5 \% \mathrm{CO}_{2}, 95 \% \mathrm{~N}_{2}+5 \%$ 
$\mathrm{CO}_{2}$ and $8 \% \mathrm{O}_{2}+5 \% \mathrm{CO}_{2}$ in nitrogen. The nerve was stimulated using square-wave stimuli of $0.01 \mathrm{msec}$ duration and variable voltage and the responses amplified and displayed on one beam of an oscilloscope, the sweep of which was triggered by the stimulator output. Single sweeps of the trace were photographed on $35 \mathrm{~mm}$ film. In all the experiments described below a nerve was used for one experiment only. Details of the technique used in producing the experimental diabetes, and of recording the evoked responses from the nerve in the gas chamber have been described earlier (Seneviratne and Peiris, 1969).

EXPERIMENT 1 The nerve mounted in the chamber was exposed to the $95 \% \mathrm{O}_{2}+5 \% \mathrm{CO}_{2}$ gas mixture and the stimulus strength required to produce a response nearly $50 \%( \pm 5 \%$ of the maximum response amplitude was determined. The nerve was then exposed to the $8 \% \mathrm{O}_{2}+5 \% \mathrm{CO}_{2}$ in $\mathrm{N}_{2}$ gas mixture and the responses to this stimulus recorded at two minute intervals for 30 minutes. One hour after the first sciatic nerve was dissected out, the second nerve was removed, immersed for 15 minutes in the oxygenated Tyrode solution, and mounted in the nerve chamber. The stimulus strength required to produce a $50 \%$ response was determined, the nerve exposed to the $95 \% \mathrm{~N}_{2}+5 \% \mathrm{CO}_{2}$ mixture, and the evoked responses to this stimulus recorded at two minute intervals for 30 minutes. Fifteen control animals were used in this series. The first sciatic nerve of each animal was exposed to the $8 \% \mathrm{O}_{2}$ mixture or the $95 \% \mathrm{~N}_{2}$ mixture alternately to ensure that the delay of one hour between the experiments was not a critical factor.

EXPERIMENT 2 One sciatic nerve was dissected out, a sample of venous blood taken for estimation of glucose content, and $20 \mathrm{u}$. soluble insulin (Boots) injected intraperitoneally. The isolated nerve was then exposed to the $8 \% \mathrm{O}_{2}$ mixture and its responses to a stimulus producing a $50 \%$ of maximum response recorded at two minute intervals. One hour later the second nerve was dissected out, the blood glucose level determined, the nerve exposed to the $8 \% \mathrm{O}_{2}$ mixture, and its responses to the sub-maximal stimulus recorded. Ten healthy animals were studied in this series.

EXPERIMENT 3 Experiment 2 was repeated using 10 diabetic rats.

\section{RESULTS}

EXPERIMENT 1 The results obtained from one experiment of this series is illustrated graphically in Fig. 1. It shows the response of a nerve in $8 \%$ $\mathrm{O}_{2}$ increasing to a maximum amplitude of $170 \%$ of its original size in the 10th minute, after which it diminishes in size, total inactivation being reached in the 22nd minute. The parallel nerve exposed to the $95 \% \mathrm{~N}_{2}+5 \% \mathrm{CO}_{2}$ mixture, however, reaches a peak amplitude of $200 \%$ in the sixth minute, and total inactivation in the 12 th minute. Figure 2

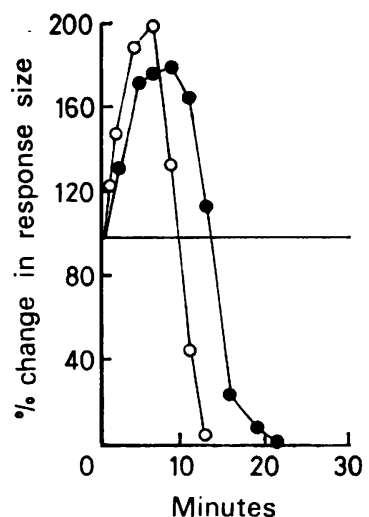

FIG. 1. The effects of hypoxia (filled circles) and anoxia (open circles) on the amplitude of the compound action potential evoked by a sub-maximal stimulus of constant size.

depicts the relationship between the maximum response amplitude and the time taken to reach it for the 15 pairs of nerves in this series and from 10 nerves in experiment 2 . In $8 \% \mathrm{O}_{2}$ the mean maximum potential size was $141.8 \%$ (range $108 \%$ $175 \%$ ), this being reached in a mean time of 6.4 minutes (range two to 10 minutes). In the $95 \% \mathrm{~N}_{2}$ mixture the corresponding values for maximum size were $165.0 \%$ (range $114-228 \%$ ) and for time

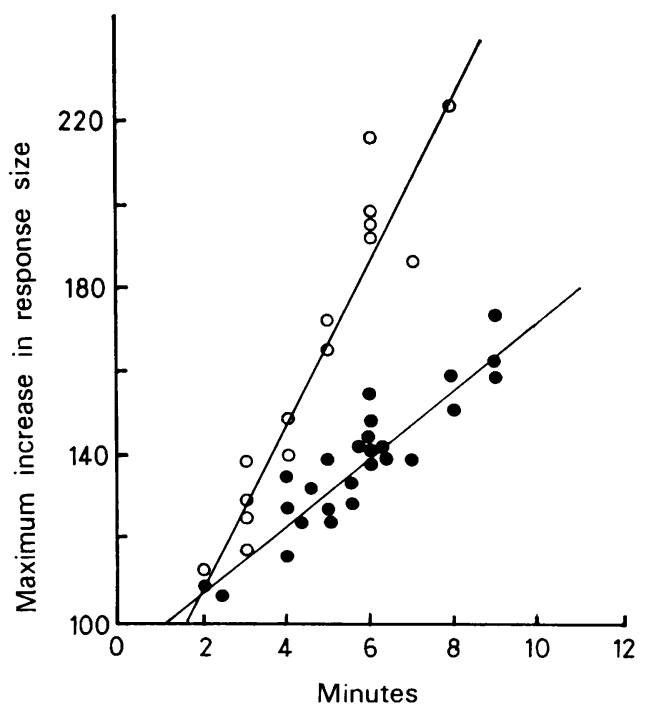

FIG. 2. Time to reach maximum increase of response amplitude. Control nerves in hypoxia (filled circles) and anoxia (open circles). Straight lines fitted by the method of least squares. 


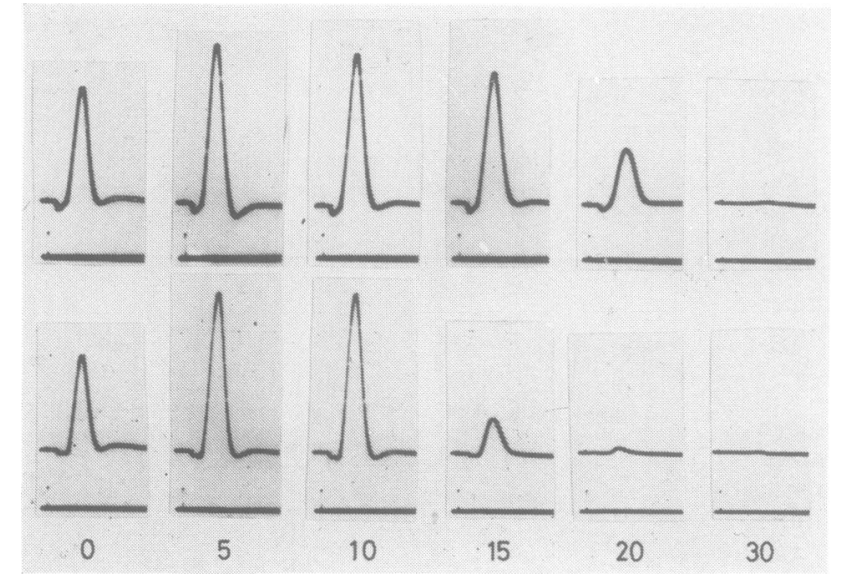

FIG. 3. Effects of hypoxia on the compound action potential evoked by a sub-maximal stimulus of constant strength. Peripheral nerve of a control rat. Upper row: nerve before insulin. Lower row: nerve after administration of insulin. In each record the lower trace monitors the stimulus. Figures indicate time in minutes.

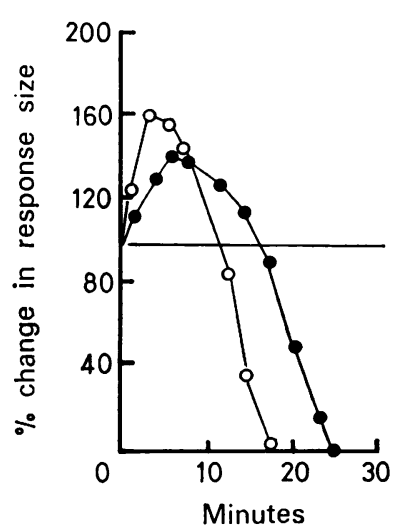

FIG. 4. Results obtained from experiment depicted in Fig. 3 plotted graphically. Percentage changes in response amplitude of nerve before insulin (filled circles) and after insulin (open circles).

4.7 minutes (range two to eight minutes). In $8 \% \mathrm{O}_{2}$ all the nerves were inactivated to less than $10 \%$ of their original size in a mean time of 24.2 minutes (range 18 to 28 minutes), whereas in $95 \% \mathrm{~N}_{2}$ the mean inactivation time was 14.4 minutes (range 10 to 19 minutes).

EXPERIMENT 2 Ten experiments were done in this series, and in each animal the blood glucose level had fallen by at least $25 \mathrm{mg} / 100 \mathrm{ml}$. (range 26 to 44 $\mathrm{mg} / 100 \mathrm{ml}$.) at the time the second nerve was dissected out for experiment. The evoked responses obtained from one such experiment are reproduced in Fig. 3, and the results of this experiment depicted graphically in Fig. 4. The changes in the behaviour of the nerves before and after insulin seen in these two curves were typical of this series.
Before insulin a maximum amplitude of $140 \%$ was reached in six minutes and near complete inactivation occurred at the 25 th minute, whereas after insulin a peak potential size of $160 \%$ was reached in four minutes, the nerve being inactivated to less than $10 \%$ of its original size by the 18 th minute.

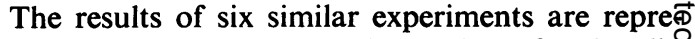
sented in Fig. 5. Figure 4 shows that after insuli po the nerves attain a larger peak amplitude after of shorter time than do the corresponding nerves before insulin. Figure 6 and the Table, which sume marizes the results obtained from the experiments of series 1 and 2 , illustrate the close similarito that exists between the behaviour of nerves from $\vec{r}^{+}$ healthy rats exposed to a $95 \% \mathrm{~N}_{2}+5 \% \mathrm{CO}_{2}$ mixture and comparable nerves from insulinized rats exposed to a gas mixture containing $8 \% \mathrm{O}_{2}$ $+5 \% \mathrm{CO}_{2}$ in nitrogen.

EXPERIMENT 3 The ten rats studied in this series had been diabetic for periods varying from 30 to 50 days and had initial blood glucose levels varying from 238 to $516 \mathrm{mg} / 100 \mathrm{ml}$. One hour after the injection of insulin the blood glucose level of each animal had fallen by at least $75 \mathrm{mg} / 100 \mathrm{ml}$. (range 76 to $210 \mathrm{mg} / 100 \mathrm{ml}$.). Theevoked responses obtained during one experiment where the nerves were exposed to the $8 \% \mathrm{O}_{2}$ mixture before and after insulin are reproduced in Fig. 7, and expressed graphically in Fig. 8.

The first nerve shows a peak response amplitude of $115 \%$ at the sixth minute, after which the nerve is slowly inactivated, but even at the end of 30 minutes the response retained $52 \%$ of its original size. In contrast, the parallel nerve, which was dissected out one hour after the administration of insulin, gave a response which was $152 \%$ of its 


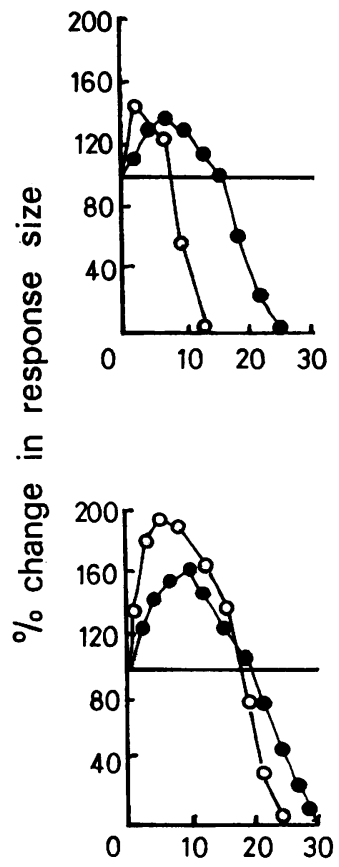

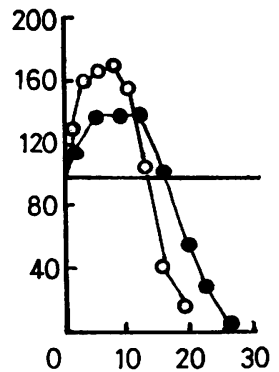

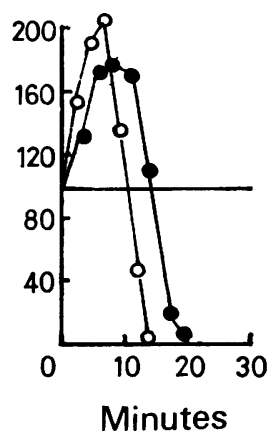

resting size at the end of six minutes, and it retained this size for a further 12 minutes. At the end of the 30 minute period of hypoxia the response was still $124 \%$ of its original amplitude. The results of six similar experiments, reproduced in Fig. 9, illustrate the characteristic changes that take place in diabetic nerves after insulin. In all of them the rising phases of the curves have steeper gradients, reach higher levels, maintain these higher levels for longer periods, and even after $\mathbf{3 0}$ minutes retain potential sizes larger than those shown by the corresponding pre-insulin nerves. There was no

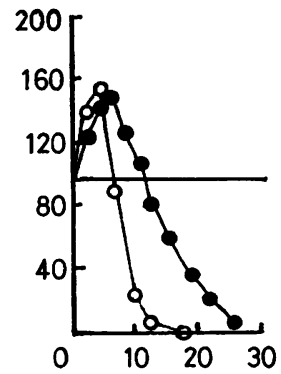

FIG. 5. Results obtained from six control nerves, showing effect of hypoxia on the size of the evoked response before insulin (filled circles) and after insulin (open circles).

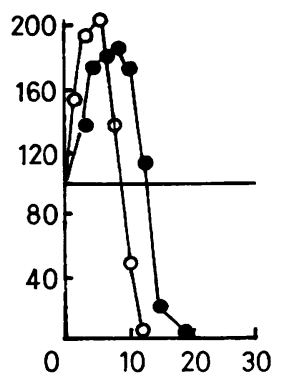

obvious relationship between the extents of these changes and the duration of the diabetic states, their original glucose levels or the levels to which the glucose levels had fallen.

\section{DISCUSSION}

There is evidence that intracellular potassium is released from the nerve during anoxia and that potassium is reabsorbed in the post-anoxic recovery period (Fenn and Gerschman, 1950; Shanes, 1950). Krnjević (1955) has shown that there is a

TABLE

EXCITABILITY CHANGES IN ANOXIC AND HYPOXIC GAS MIXTURES

\begin{tabular}{|c|c|c|c|c|c|c|}
\hline \multirow{3}{*}{ Exp. 1} & \multirow{3}{*}{$\begin{array}{l}\text { In } 8 \% \mathrm{O}_{2} \\
(\mathrm{~N}=15) \\
\text { In } \mathrm{N}_{2} \\
(\mathrm{~N}=15)\end{array}$} & \multirow{3}{*}{$\begin{array}{c}\begin{array}{c}\text { Maximum potential } \\
\text { size }(\%)\end{array} \\
108-175 \\
\text { (Mean 141.8) } \\
114-228 \\
\text { (Mean 165) }\end{array}$} & \multicolumn{2}{|c|}{$\begin{array}{l}\text { Time to reach } \\
\text { maximum size }(\mathrm{min})\end{array}$} & \multicolumn{2}{|c|}{$\begin{array}{l}\text { Time to reach } \\
90 \% \text { inactivation (min) }\end{array}$} \\
\hline & & & $\begin{array}{l}2 \cdot 0-10 \cdot 0 \\
(\text { Mean 6.4) }\end{array}$ & \multirow{2}{*}{$P$ is $<\cdot 001$} & $\begin{array}{l}18 \cdot 0-28 \cdot 0 \\
\text { (Mean } 24 \cdot 2)\end{array}$ & \multirow{2}{*}{$P$ is $<\cdot 001$} \\
\hline & & & $\begin{array}{l}2 \cdot 0 \cdot 8 \cdot 0 \\
(\text { Mean } 4 \cdot 7)\end{array}$ & & $\begin{array}{l}10 \cdot 0-19 \cdot 0 \\
(\text { Mean 14.4) }\end{array}$ & \\
\hline \multirow{2}{*}{ Expt. 2} & $\begin{array}{l}\text { Before } \\
\text { insulin }(N=10)\end{array}$ & $\begin{array}{c}140-176 \\
(\text { Mean } 153 \cdot 2)\end{array}$ & $\begin{array}{l}6 \cdot 0-9 \cdot 0 \\
(\text { Mean } 7 \cdot 4)\end{array}$ & \multirow{2}{*}{$P$ is $<.001$} & $\begin{array}{l}18 \cdot 0-26 \cdot 0 \\
\text { (Mean 24.1) }\end{array}$ & \multirow{2}{*}{$P$ is $<.001$} \\
\hline & $\begin{array}{l}\text { After } \\
\text { insulin }(N=10)\end{array}$ & $\begin{array}{c}120-206 \\
\text { (Mean 167.4) }\end{array}$ & $\begin{array}{l}3 \cdot 8 \cdot 6 \cdot 0 \\
(\text { Mean 4.9) }\end{array}$ & & $\begin{array}{l}11 \cdot 0-22 \cdot 0 \\
\text { Mean } 16 \cdot 20\end{array}$ & \\
\hline
\end{tabular}

Values of $P$ determined by Student's $t$ test. 


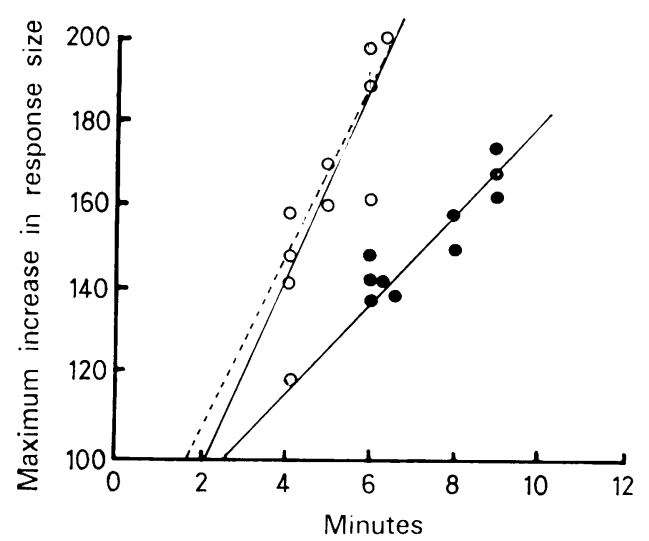

FIG. 6. Time to reach maximum increase of response amplitude. Ten pairs of control nerves in hypoxia before insulin (filled circles) and after insulin (open circles). Continuous straight lines fitted by the method of least squares. Interrupted line indicates slope of line obtained from anoxic nerves.

slow efflux of $\mathrm{K}^{\prime}$ from cat nerve when it is suspended in oxygenated isotonic sucrose, $10 \%$ of the total intracellular $\mathrm{K}^{\prime}$ diffusing out within 10 minutes. When the nerve was exposed to chloroform fumes at $37^{\circ} \mathrm{C}$ for 20 minutes beforehand, the $\mathrm{K}^{\prime}$ efflux was exponential with a very much shorter time constant, $75 \%$ of the total $\mathrm{K}^{\prime}$ diffusing out with a half period of 3.5 minutes. Maruhashi and Wright (1967) have shown that oxidative metabolic energy is required to maintain the resynthesis of the ATP of the nerve membrane enzyme complex. When deprived of this metabolic energy $\mathrm{Ca}^{*}$ is released from the membrane, increasing its permeability (Frankenhaeuser and Hodgkin, 1957; Kimizuka and Koketsu, 1963), and permitting the $\mathrm{Na}^{\prime} \mathrm{K}^{\prime}$ to migrate down their concentration gradients.

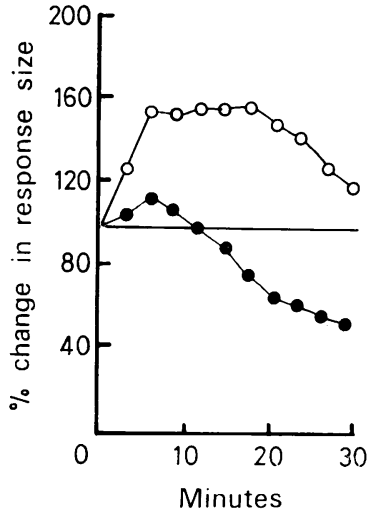

FIG. 8. Results obtained from experiment depicted in Fig. 7 plotted graphically. Percentage changes in response amplitude of diabetic nerve before insulin (filled circles) and after insulin (open circles).

The accumulation of $\mathrm{K}^{\prime}$ in the periaxonal spaceso would reduce the resting membrane potential of the nerve fibres (Shanes, 1950; Huxley and Stämpfli 1951; Adrian, 1956). The initial depolarization produced in this manner would, in effect, resulf in an increase of the excitability of the nerve by lowering the threshold voltage required for stimu lation. Continued increase of the periaxonal $\mathrm{K}$ ? concentration would, however, cause more extensive depolarization which results in failure of action potential generation and conduction block. This sequence of change would account for the transient phase of hyperexcitability seen in peripheral nerves in vitro at a stage before they are inactivated by the anoxia (Heinbecker, 1929; Lehmann, 1937; Seneviratne and Peiris, 1969). Similar changes have

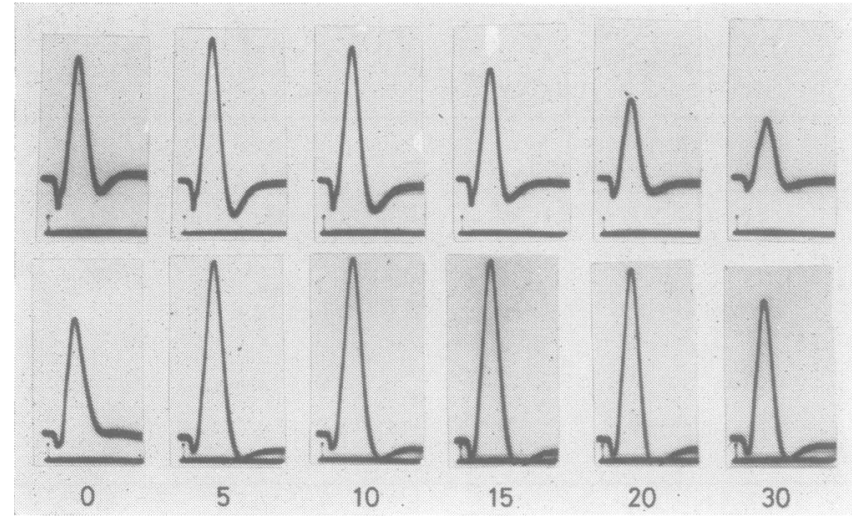

FIG. 7. Effects of hypoxia on the responses evoked by a sub-maximal stimulus of constant strength. Peripheral nerve of an alloxandiabetic rat. Upper row: nerve before insulin. Lower row: nerve after insulin. In each record the lower trace monitors the stimulus. Figures indicate time in minutes. 


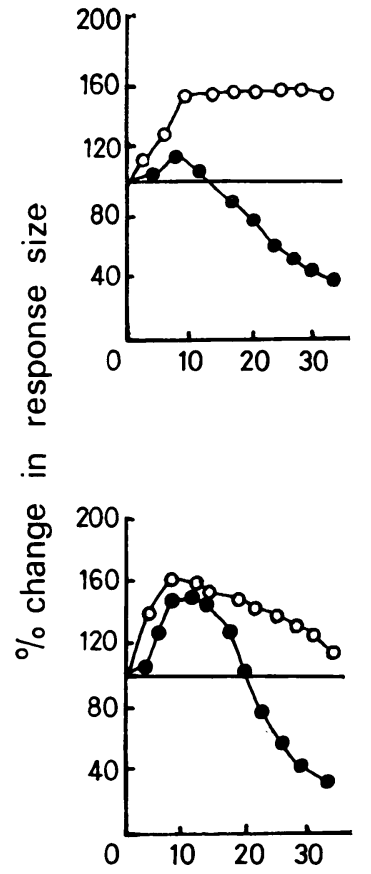

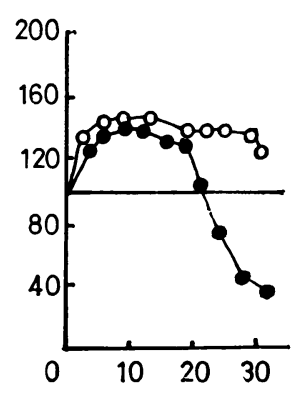

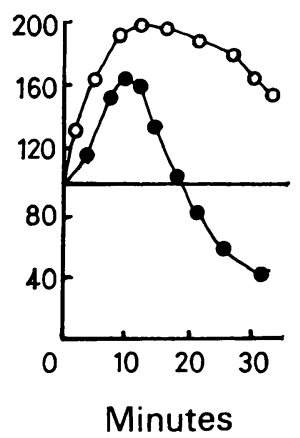

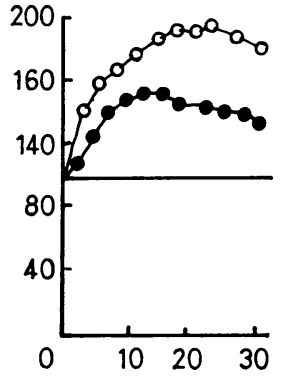

FIG. 9. Results obtained from six diabetic nerves showing effects of hypoxia on the response amplitude before insulin (filled circles) and after insulin (open circles).

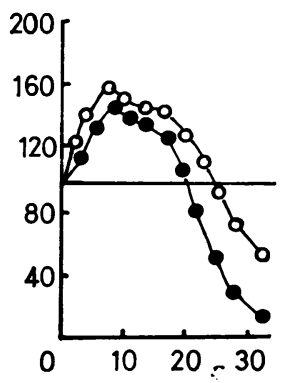

been demonstrated in human peripheral nerves during experimental limb ischaemia (Kugelberg, 1946; Fullerton, 1963). Seneviratne and Peiris (1968a) measured excitability changes in the sensory fibres of the median nerve during vascular occlusion by observing changes in the size of the responses evoked by a constant sub-maximal stimulus of critical size. It was shown that an increase in the excitability of fibres ordinarily just beyond the range of this stimulus would reduce their thresholds and render them excitable. Thus increases in excitability would result in the recruitment of additional fibres, this change being manifest as an increase in the size of the recorded compound action potential. Conversely, a decrease of excitability would be indicated by a diminution in the size of the recorded potential. That a high surface $\mathrm{K}^{\prime}$ concentration is sufficient to produce depolarization block is evident from the studies of Shanes (1951) who showed that washing of the nerve with oxygen-free Ringer's solution alone was sufficient to restore functional activity in anoxic frog nerve fibres.

If surface $\mathrm{K}^{\prime}$ concentrations are to play a critical role in the depolarization process, it would be necessary to postulate the existence of diffusion barriers in the nerve which would restrict the free

diffusion of ions from the periaxonal to the extracellular fluid compartment. It is conceivable that the functional changes described above could occur either if individual axons were surrounded by diffusion barriers or if groups of axons were enclosed within a common barrier. There is general agreement that nerves are surrounded by relatively impermeable external sheaths (Feng and Gerard, 1930; Feng and Liu, 1949; Rashbass and Rushton, 1949; Crescitelli, 1951; Dainty and Krnjević, 1955), and it has been suggested by Krnjević (1954) that the function of such a sheath may be to preserve the specific character of the internal environment of nerve tissue. There is, however, no agreement as to the precise site of the barrier. Causey and Palmer (1953) viewed the epineurium as the diffusion barrier, whereas Huxley and Stämpfli (1951); Krnjević (1955); Thomas (1963); and Gamble (1964) favoured the perineurium. The Schwann cells of myelinated fibres are ensheathed by a basement membrane which is continuous across the nodes of Ranvier from one internode to another. Haftek and Thomas (1968) indicate that the neurilemmal sheath, made up of the Schwann cell basement membrane and the inner endoneurial collagen sheath of Plenk and Laidlaw, is a continuous elastic tube which remains intact even during 
nerve degeneration, serving to define the channels within which the Schwann cells proliferate during nerve regeneration.

The results obtained in experiment 1 provide evidence in favour of the hypothesis outlined above. Theory predicts that the $\mathrm{K}^{\prime}$ efflux would be larger when the nerve is in the anoxic gas mixture than when it is in the $8 \% \mathrm{O}_{2}$ mixture; it is therefore anticipated that during anoxia the $\mathrm{K}^{\prime}$ accumulating within the diffusion barrier would attain the concentrations required for critical depolarization of the membrane and for inactivation of the membrane at time intervals which are shorter than for comparable nerves during hypoxia. The results of experiment 1 indicate that, with the nerve in $8 \% \mathrm{O}_{2}$, the mean time to reach maximum amplitude was 6.4 minutes, and to reach inactivation 24.2 minutes, whereas in the $95 \% \mathrm{O}_{2}+5 \% \mathrm{CO}_{2}$ mixture the corresponding times were reduced to 4.7 and 14.4 minutes.

Another observation derived from the results of experiments 1,2 , and 3 is that the maximum amplitudes reached tend to be greater as the times required to reach this become shorter. It has been argued above that increase in response size is due to progressive recruitment of new fibres of higher threshold, as continuing depolarization lowers their thresholds to levels which make them responsive to the test stimulus. Continued accumulation of $\mathbf{K}^{\prime}$ would, however, also tend to depolarize towards inactivation levels the low threshold fibres which earlier contributed to the response. Since the size of the response at any given time represents the summated contributions of the active fibres, it follows that this potential would be increased by the contributions being made by the freshly recruited fibres and diminished as a result of the progressive withdrawal of the low threshold fibres. In this situation it is conceivable that a more rapid increase of the periaxonal $\mathrm{K}^{\prime}$ concentration would, during a transient period, permit of a greater degree of synchronization of the recruitment process. This would allow of occasions when nearly all the fibres of the compound nerve are responsive, at a given moment, to the submaximal test stimulus.

Zierler (1959) showed that insulin produces an influx of $\mathrm{K}^{\prime}$ into excised rat muscle, and that it increases the resting membrane potential of muscle by about $5 \mathrm{mV}$. There is also evidence (Gamble, 1962) that $\mathrm{K}^{\prime}$ ions are required for oxidative phosphorylation in mitochondria, and that $\mathrm{K}^{\prime}$ ions move into cells when glucose is taken up from the extracellular fluid into tissue cells and converted into glycogen. Field and Adams (1964) have shown that insulin increases the in vitro uptake of glucose by alloxan-diabetic rabbit nerves and $O$. A. Peiris
and suggest that insulin in vitro reverses the meta- $\frac{\overbrace{\mathbb{O}}}{Z}$
bolic defect of diabetic nerves which is evidenced by its depleted resting glycogen levels. In experiments 2 and 3 insulin has been used to increase the of

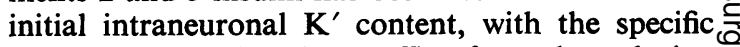
object of increasing the $\mathrm{K}$ efflux from them during hypoxia.

In experiment 2 the results obtained from such nerves are compared with those from control nerves in $8 \% \mathrm{O}_{2}$. It is expected that nerves with an in-? creased intraneuronal $\mathrm{K}^{\prime}$ content would, during $\overrightarrow{\overrightarrow{\mathrm{s}}}$ hypoxia, produce a more rapid build up of periaxonal $\mathbf{K}^{\prime}$ concentrations within their impermeable? barriers, leading to a more rapid development of the hyperexcitable and inexcitable states. $\frac{\vec{\phi}}{\sigma}$ This is borne out by the results of experiment 2 . Control nerves in $8 \% \mathrm{O}_{2}$ reached maximum excitability in a mean time of 7.4 minutes and were $\vec{\circ}$ inactivated by the 24th minute, whereas after insulin the corresponding times were reduced to $\vec{\omega}$ 4.9 and 16.2 minutes.

In experiment 3 the nerves from the diabetic animals were first exposed to the $8 \% \mathrm{O}_{2}$ mixture, and the results obtained are essentially similar t $\theta$ those published earlier (Seneviratne and Peiris, $\omega$ 1969). The characteristic differences between tie behaviour of these nerves and those from healtion rats relate to the extent of inactivation by the hypoxia and to the time relationships of the earty phase of hyperexcitability. The results show thêt there is significant delay in the rate at which nerve is subsequently inactivated. These changs could be related to a slower build up of $\mathrm{K}^{\prime}$ cont-. centration in the periaxonal spaces of the diabetic nerve. Since the $\mathbf{K}^{\prime}$ concentration in the space is determined by the relative rate of $K^{\prime}$ efflux from the hypoxic nerve and the rate at which it could diffuse out across the barrier, it follows that a slower $K^{\prime} \stackrel{\square}{\unrhd}$ build up could be accounted for by a change $\overrightarrow{\vec{F}}$ in either of these states. Our results show that 3 the rate of increase of excitability in the postinsulin diabetic nerves is consistently greater than in the pre-insulin nerves. This is evidence that the rate of $K^{\prime}$ build up in the space is now faster than before, a circumstance which should lead to quicker: inactivation were the barrier an impermeable 3 one. The results, however, show that this does not occur, but that inactivation occurs at an even slower rate than in the pre-insulin nerve. It is therefore ${ }_{\circ}$ necessary to postulate that the diffusion barrier? limiting the periaxonal space in the diabetic nerve is a permeable one, permitting the $K^{\prime}$ to diffuse out more freely across it.

Thickening of the basement membrane of smalh blood vessels has been consistently demonstrated in the retina, kidney, skin, stomach, skeletal muscle 
vasa vasorum of the aorta, and the vasa nervorum of peripheral nerve (Fagerberg, 1966). The characteristic lesions of diabetic microangiopathy with retinopathy, glomerulosclerosis, and diffuse basement membrane thickening have also been demonstrated in dogs made diabetic by bovine pituitary growth hormone or alloxan (Engerman and Bloodworth, 1965). Spiro (1963) has suggested that the diversion of hexose along insulin independent pathways could result in the over-production of the basement membrane substance and other glycoproteins, which could account for the observed thickening. Blumenthal, Hirata, Owens, and Berns (1964) have suggested that the basement membrane abnormality may be a manifestation of a more generalized antigen-antibody reaction.

Bischoff (1968) demonstrated a significant thickening of the basement membrane surrounding the Schwann cells of the peripheral nerves of diabetic subjects associated with the duplication and multiplication of the membrane. He observes that in order of frequency of occurrence of morphological changes in these nerves, hyperplasia of the basement membrane is the most prominent. This structural change is, however, not characteristic of any particular aetiology because reduplication of the membrane also occurs in regenerating nerves (Nathaniel and Pease, 1963). Simpson (1962) has suggested that the role of one or other of the axon coverings is paramount in determining the velocity changes seen in disease and nerve compression experiments. He discussed the possibility that this could be due to physical distortion of the lipid-protein molecular arrangement in myelin or of the perineurium, or to a more direct effect on the excitable membrane of the nerve fibre affecting the rate of trans-membranal exchange of electrolytes. Bischoff (1968) suggests that the only early abnormality of ultrastructure which could have some bearing on the functional disturbance in diabetic neuropathy is the thickening and reduplication of the basement membrane surrounding the Schwann cell. He argues that hyperplasia of this exchange barrier would not be without effect on metabolic exchange, and that this could be expected to cause a delay in the development of the action potential which would result in a diminution in the overall speed of conduction of the nerve impulse. More recent studies, however, indicate that the lowering of the conduction velocity is due to the paranodal demyelination which occurs in these nerves. Seneviratne and Peiris (1968b) have since shown that the resistance of the nerves of diabetic subjects to ischaemic inactivation can be demonstrated even in the presence of normal motor and sensory nerve conduction velocities. In this paper it is suggested that the resistance is due primarily to an increased permeability of the periaxonal diffusion barriers to $\mathrm{K}^{\prime}$. Bischoff's (1968) observation of thickened and reduplicated basement membranes in diabetic nerves is not necessarily incompatible with this increased permeability to the diffusion of electrolytes, because the thickening of the basement membrane of the glomerular capillaries seen in a variety of kidney lesions is invariably accompanied by an increase of its permeability to the plasma proteins.

We are grateful to Messrs. K. S. A. B. Fernando and S. Vairavanathan for their invaluable technical assistance. One of us (K.N.S.) is in receipt of research grants from the University of Ceylon, Colombo, and the Ministry of Scientific Research of the Government of Ceylon.

\section{REFERENCES}

Adrian, R. H. (1956). The effect of internal and external potassium concentration on the membrane potential of frog muscle. J. Physiol. (Lond.), 133, 631-658.

Bischoff, A. (1968). Diabetic neuropathy. Germ. med. Mth., 13, 214-217.

Blumenthal, H. J., Hirata, Y., Owens, C. T., and Berns, A. W. (1964). In Small Blood Vessel Involvement in Diabetes Mellitus. Edited by M. D. Siperstein, A. R. Colwell, and K. Meyer. Amer. Inst. Biol. Sci: Washington, D.C.

Castaigne, P., Cathala, H. P., Dry, J., and Mastropaolo, C. (1966). Les réponses des nerfs et des muscles à des stimulations électriques au cours d'une épreuve de garrot ischémique chez l'homme normal et chez le diabétique. Rev. neurol., 115, 61-66.

Causey, G., and Palmer, E. (1953). The epineurial sheath of a nerve as a barrier to the diffusion of phosphate ions. J. Anat. (Lond.), 87, 30-36.

Crescitelli, F. (1951). Nerve sheath as a barrier to the action of certain substances. Amer.J. Physiol., 166, 229-240.

Dainty, J., and Krnjević, K. (1955). The rate of exchange of ${ }^{24} \mathrm{Na}$ in cat nerves. J. Physiol. (Lond.), 128, 489-503.

Engerman, R. L., and Bloodworth, J. M. B., Jr. (1965). Experimental diabetic retinopathy in dogs. Arch. Ophthal., 73, 205-210.

Fagerberg, S. E. (1966). The angiopathy of diabetes, in Diabetes Mellitus, pp. 53-62. Edited by L. J. P. Duncan, Pfizer Medical Monographs I, Edinburgh, Edinburgh University Press.

Feng, T. P., and Gerard, R. W. (1930). Mechanism of nerve asphyxiation: with a note on the nerve sheath as a diffusion barrier. Proc. soc. exp. Biol. (N.Y.), 27, 1073-1076.

Feng, T. P., and Liu, Y. M. (1949). The connective tissue sheath of the nerve as an effective diffusion barrier. J. cell. comp. Physiol., 34, 1-16.

Fenn, W. O., and Gerschman, R. (1950). The loss of potassium from frog nerves in anoxia and other conditions. J. gen. Physiol., 33, 195-204.

Field, R. A., and Adams, L. C. (1964). Insulin response of peripheral nerve 1. Effects on glucose metabolism and permeability. Medicine (Baltimore), 43, 275-279.

Frankenhaeuser, B., and Hodgkin, A. L. (1957). The action of calcium on the electrical properties of squid axons. J. Physiol. (Lond.), 137, 218-244. 
Fullerton, P. M. (1963). The effect of ischaemia on nerve conduction in the carpal tunnel syndrome. $J$. Neurol. Neurosurg. Psychiat., 26, 385-397.

Gamble, J. L. (1962). Retention of potassium by mitochondria. Amer.J. Physiol., 203, 866-890.

Gamble, H. J. (1964). Comparative electron-microscopic observations on the connective tissues of a peripheral nerve and a spinal nerve root in the rat. J. Anat. (Lond.), 98, 17-25.

Gregersen, G. (1968). A study of peripheral nerves in diabetic subjects during ischaemia. J. Neurol. Neurosurg. Psychiat., 31, 175-181.

Haftek, J., and Thomas, P. K. (1968). Electron-microscope observations on the effects of localized crush injuries on the connective tissues of peripheral nerve. J. Anat. (Lond.), 103, 233-243.

Heinbecker, P. (1929). Effect of anoxemia, carbon dioxide and lactic acid on electrical phenomena of myelinated fibers of the peripheral nervous system. Amer. $J$. Physiol., 89, 58-83.

Huxley, A. F., and Stämpfli, R. (1951). Effect of potassium and sodium on resting and action potentials of single myelinated nerve fibres. J. Physiol. (Lond.), 112, 496508.

Kimizuka, H., and Koketsu, K. (1963). Changes in the membrane permeability of frog's sartorius muscle fibers in Ca-free EDTA solution. J. gen. Physiol., 47, 379-392.

Krnjevic, K. (1954). The connective tissue of the frog sciatic nerve. Quart. J. exp. Physiol., 39, 55-72.

Krnjević, K. (1955). The distribution of $\mathrm{Na}$ and $\mathrm{K}$ in cat nerves. J. Physiol. (Lond.), 128, 473-488.

Kugelberg, E. (1946). Injury activity and trigger zones in human nerves. Brain, 69, 310-324.

Lehmann, J. E. (1937). The effect of asphyxia on mammalian A nerve fibers. Amer. J. Physiol., 119, 111-120.

Maruhashi, J., and Wright, E. B. (1967). Effect of oxygen lack on the single isolated mammalian (rat) nerve fiber. J. Neurophysiol., 30, 434-452.

Nathaniel, E. J. H., and Pease, D. C. (1963). Collagen and basement membrane formation by Schwann cells during nerve regeneration. J. Ultrastruct. Res., 9, 550-560.

Rashbass, C., and Rushton, W. A. H. (1949). The relation of structure to the spread of excitation in frog's sciatic trunk. J. Physiol. (Lond.), 110, 110-135.

Seneviratne, K. N., and Peiris, O. A. (1968a). The effect of $\overrightarrow{0}$ ischaemia on the excitability of human sensory nerve. J. Neurol. Neurosurg. Psychiat., 31, 338-347.

Seneviratne, K. N., and Peiris, O. A., (1968b). The effect of ischaemia on the excitability of sensory nerves in diabetes mellitus. J. Neurol. Neurosurg. Psychiat., 31, 348-353.

Seneviratne, K. N., and Peiris, O. A., (1969). The effects of hypoxia on the excitability of the isolated peripheral nerves of alloxan-diabetic rats. J. Neurol. Neurosurg. Psychiat., 32, 462-469.

Shanes, A. M. (1950). Electrical phenomena in nerve. 1. Squid giant axon. J. gen. Physiol., 33, 57-74.

Shanes, A. M. (1951). Potassium movement in relation to nerve activity. J. gen. Physiol., 34, 795-807.

Simpson, J. A. (1962). Conduction velocity of peripheral nerves in human metabolic disorders. Electroenceph. clin. Neurophysiol, Suppl., 22, 36-43.

Spiro, R. G. (1963). Glycoproteins and diabetes. Diabetes, 12, 223-230.

Steiness, I. (1959). Vibratory perception in diabetics during arrested blood flow to the limb. Acta med. scand., 163, 195-205.

Steiness, I., (1961a). Vibratory perception in non-diabetic subjects during ischaemia, with special reference to the conditions in hyperglycaemia, after carbohydrate starvation and after [cortisone administration. Act med. scand., 169, 17-26.

Steiness, I. (1961b). Influence of diabetic status o⿱一 vibratory perception during ischaemia. Acta med? scand., 170, 319-338.

Thomas, P. K. (1963). The connective tissue of peripher备 nerve: an electron-microscope study. J. Anat. (Lond 97, 35-44.

Zierler, K. L. (1959). Effect of insulin on membrane potenti角 and potassium content of rat muscle. Amer. J. Physio르 197, 515-523. 